\title{
De cómo el patrimonio puede ayudarnos a entender la auténtica historia de la mujeres
}

Oliva Cachafeiro Bernal | coordinadora de actividades del museo de Arte Africano Arellano Alonso, Universidad de Valladolid, y gestora cultural

URL de la contribución <www.iaph.es/revistaph/index.php/revistaph/article/view/3730>

El debate sobre la presencia de las mujeres en el mundo de la creación artística ha avanzado mucho en los últimos años. Mujeres pintoras, escritoras, cineastas, performers, ilustradoras..., empiezan a ser conocidas, y reconocidas, gracias al impulso de los estudios de género en los años 70 . Y aunque aún falta un vasto camino por recorrer, al menos existe conciencia sobre lo imprescindible de sacar a la luz los nombres y trabajos de estas mujeres. Las más jóvenes tienen cada vez mayor protagonismo en la prensa y publicaciones especializadas, pero aún las estadísticas demuestran que su presencia en museos y/o eventos artísticos es inferior a la de los artistas-hombres ${ }^{1}$.

Si esto sucede en el ámbito de la creación, la situación se agrava en el caso del estudio y puesta en valor del patrimonio en el que se integra la perspectiva de género. La única solución ante esto: la educación. Y no sólo en la escuela, sino en la propia universidad, que debe concienciarse de la necesidad de introducir esta temática tanto en los estudios de grado de Historia del Arte, como en las facultades de Educación. La formación de los futuros formadores, que con su ejemplo y enseñanza contribuyan a difundir lo imprescindible de este enfoque entre el alumnado, es esencial. ¿Es esto fácil? En absoluto. Y una de las razones es el empecinamiento de muchos de los insignes doctores y catedráticos en continuar impartiendo "doctrinas" decimonónicas.

No son capaces de reconocer que al dejar de lado la perspectiva de género están mostrando una historia sesgada, de la que se ha expulsado a la mitad de sus protagonistas: las mujeres. En el caso de aparecer, lo hacen como "musas", idealizadas, indolentes, sumisas, bellas, intangibles... Pero, ¿dónde están las mujeres reales que trabajaban, padecían y sostenían a sus familias? Sometidas

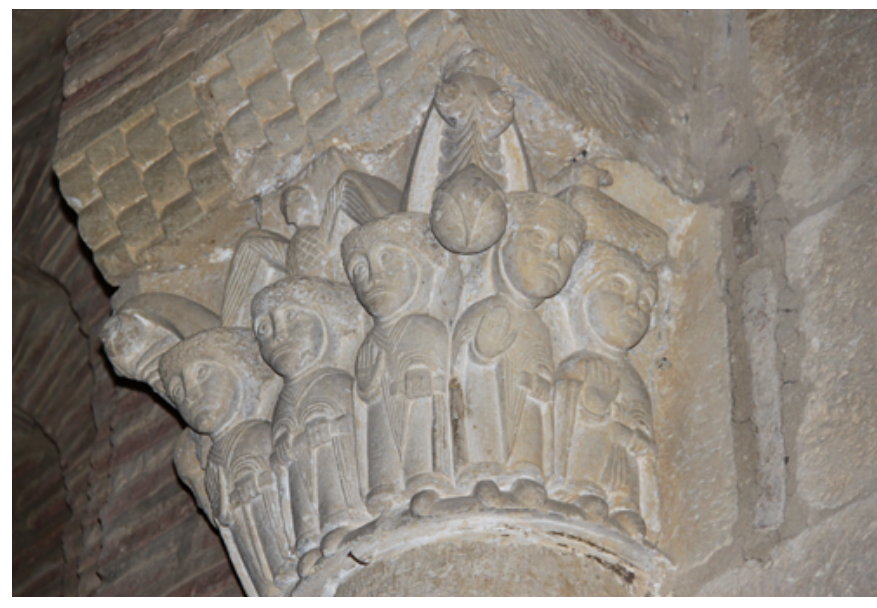

Capitel de las siete monjas en el monasterio de San Pedro de las Dueñas (León) | foto Oliva Cachafeiro

a la autoridad masculina a lo largo de toda su vida (primero la del padre, después el hermano, el marido, los hijos..., y si no el señor feudal o el cura), sobrevivían para que después su memoria desapareciera sin más.

Muchas de esas mujeres, sin embargo, también inventaron, dibujaron, esculpieron, influyeron en política..., e incluso buscaron crear sus propios espacios donde sentirse libres. $Y$ ello también se refleja en el patrimonio. Un ejemplo claro son los monasterios del medioevo. Siempre sujetos a una Regla (generalmente escrita por un fundador) y sometidos a la jerarquía eclesiástica, se transformaron en ocasiones en baluartes de lucha y resistencia desde los que las mujeres-monjas reclamaban su autonomía, rompiendo con las imposiciones de sociedades totalmente patriarcales.

Esos espacios cerrados, separados del resto del mundo por elevados muros, se convirtieron en refugio, e incluso en la única opción, para jóvenes que si no podían o no 
lograban casarse, no hubieran tenido probablemente más alternativa que vivir de la caridad o dedicarse a la prostitución. Se trataba pues de una salida obligada que en muchos casos se convirtió en una "bendición", pues las alejó de la autoridad familiar y les ofreció un modo de vida. Una vez alí pudieron desarrollar sus vocaciones reales como escritoras, pintoras, músicas y tomar sus propias decisiones, enfrentándose también en muchos casos a la autoridad religiosa y actuando al margen de ella, con independencia pese a las amenazas. ¿Quién puede negar que una de las mujeres con mayor autoridad en la Castilla medieval era la abadesa de Las Huelgas de Burgos? por poner un ejemplo.

Las edificaciones monásticas se adaptaban a sus formas de vida $y$, pese a que en lo básico seguían lo establecido en la Regla a la que pertenecían, añadían estancias para sus criadas, zonas de recreo, o espacios para el estudio. Visitar esos edificios actualmente es recordar pues, a través del patrimonio, toda una forma de vida.

Otro caso peculiar es el de los beguinajes flamencos, uno de los pocos sitios incluidos en la Lista del Patrimonio Mundial directamente relacionados con la historia y la vida femeninas. En este caso eran mujeres laicas que de forma libre decidían agruparse en comunidades para ejercer el bien, pero sin estar sometidas a la jerarquía eclesiástica. Los primeros ejemplos surgieron en el siglo XII en diversas ciudades de la actual Bélgica, como Flandes. Las beguinas se dedicaban a la educación de las niñas, el cuidado de enfermos, la alimentación de los necesitados..., pero además cultivaban la música, la pintura y la literatura. Procedentes de todas las clases sociales, e incluso algunas casadas, vivían en celdas, casas o grupos de viviendas. Llegaron a levantar verdaderos complejos arquitectónicos formados por varias edificaciones, tanto civiles como religiosas, entre las que se incluían espacios abiertos.

Esas construcciones, hoy visitables, permiten una vez más conocer un aspecto de la historia femenina que demuestra claramente cómo las mujeres medievales intentaron romper con el sometimiento de una sociedad patriarcal. Su visita se convierte pues en una lección de historia; el patrimonio como muestra de vida. Y esta es la fuerza del mismo que se debe reivindicar y potenciar.

¿Cuántos de los estudiantes de arte o de historia en general conocen su existencia? En el caso de los monasterios y conventos es más fácil afirmar que bastantes, pero si nos centramos en el de los beguinajes flamencos, ¡mejor no preguntar! Algo decepcionante porque demuestra que el heteropatriarcado sigue dominando el sistema educativo, pero también porque ambos espacios serían uno de los claros ejemplos de cómo el patrimonio puede ayudar a entender mejor la evolución social, ilustrando la experiencia de unas mujeres que intentaron luchar contra el régimen establecido y que se les había impuesto simplemente por "la mala suerte" de haber nacido mujeres. ¡Cómo es posible, por tanto, hurtar una parte de nuestro pasado que es fundamental para conocer nuestro presente!

\section{NOTA}

1. Un ejemplo de ello es que el porcentaje de mujeres en ARCO Madrid 2015 sólo llegó al 23\%.

\section{BIBLIOGRAFÍA}

- INFORME MAV \#14: Presencia de mujeres artistas en ArcoMadrid'15. En MAV. Mujeres en las artes visuales [en línea] $<$ http://www.mav.org.es/index.php/observatorio/informes-ypropuestas> [Consulta: 27/01/2016]

- RÖSSLER, M. (2015) ¿Patrimonio Mundial con perspectiva de género? Análisis de la aplicación de la Convención de la UNESCO sobre el Patrimonio Mundial (1972) [en línea]. En Igualdad de género, patrimonio y creatividad. Argentina: Centro Internacional para la Promoción de los Derechos Humanos bajo el auspicio de la UNESCO, 2015 <http://unesdoc.unesco.org/ images/0023/002316/231661S.pdf> [Consulta: 27/01/2016]

- TOBELlA, A. (2013) Muere la última beguina. En Blog El País Mujeres [en línea], 24 de abril de $2013<$ http://blogs.elpais. com/mujeres/2013/04/muere-la-\%C3\%BAltima-beguina.html> [Consulta: 28/01/2016] 